\title{
SBA-3-based Nanocatalysts Application in Nile Blue Removal from Wastewater
}

\author{
Violeta Niculescu, Marius Miricioiu, Amalia Soare, Adriana Marinoiu, Daniela Ebrasu-Ion, \\ Marius Constantinescu and Felicia Bucura
}

National Research and Development Institute for Cryogenics and Isotopic Technologies - ICSI

Ramnicu Valcea, 4th Uzinei Street, 240050 Ramnicu Valcea, Romania

\begin{abstract}
Various mesoporous molecular sites, such as SBA, have been synthesized using selfassembly of surfactants, with low and / or high molecular weight copolymers. Mesoporous molecular sieves such as SBA-3 can be synthesized at room temperature under acidic conditions. The method is similar to that of SBA-15, except for the template, which may be a low molecular weight quaternary alkylammonium salt. For this reason, the development of this material is interesting for applications in catalysis and redox deposition of metals on a nano-metric scale. Also, various catalysts have been applied for the oxidation of organic compounds in water, including the organic dyes. Nile Blue is a fluorescent dye, used in various bio-applications and it is considered a contaminant in water.

In this study, catalysts obtained by immobilisation of transitional metals on SBA-3 mesoporous silica were used to oxidize the Nile Blue from wastewater. The obtained silica support and catalysts were characterized by SEM, TG, UV-VIS, FTIR, BET surface area and pore size distribution measurements.

The oxidation was carried out in a batch reactor at room temperature and pressure. The decolourization experiments were monitored by UV-VIS spectrophotometry. The oxidation reactions followed the first order kinetics. The catalysts could be recovered and reused.

The Nile Blue from wastewater can be oxidized by catalysts obtained by impregnation of transitional metals on SBA-3 suport, the oxidation products being less harmful for the environment and for the aquatic systems.
\end{abstract}

Keywords: dye; nanocatalyst; silica; wastewater

Acknowledgements: The work has been funded by the Romanian Ministry of Scientific Research and Innovation, NUCLEU Program-Financing Contract no. 9N/2019, under Project PN 19110301 "Studies on the obtaining and improvement of the acido-basic properties of the nanoporous catalytic materials for application in wastes valorization".

Publisher's Note: MDPI stays neutral with regard to jurisdictional claims in published maps and institutional affiliations.

(C) 2020 by the authors. Submitted for possible open access publication under the terms and conditions of the Creative Commons Attribution (CC BY) license (http://creativecommons.org/licenses/by/4.0/). 